\title{
Evaluation of the Modified Mini-SLET Technique in the Surgical Treatment of Primary Pterygium
}

\author{
Jose DAC, Gian Francisco Rodrigues CDS, Luma Pinheiro EP, Samira \\ Gracielle PCB, Julia Brandao De PTC and Jose Bonifacio B* \\ Federal University of Maranhao, Brazil
}

*Corresponding author: Jose Bonifacio Barbosa, Federal University of Maranhao,

\section{Research Article}

Volume 3 Issue 3

Received Date: April 23, 2018

Published Date: May 30, 2018

Avenida Holandeses Cond Farol Da Ilha Torre 6 Apt. 22 Sao Luis - Maranhao, Brazil, Email: bonioftalmo@hotmail.com

\section{Abstract}

Objective: To evaluate the efficacy of the modified mini-SLET (simple limbal epithelial transplantation) technique in the surgical treatment of primary pterygium.

Methods: This was a case series involving 31 eyes of consecutive patients with primary pterygium who were treated with the modified mini-SLET technique. After pterygium excision, a 2x4-mm fragment of healthy conjunctiva was removed from the superior temporal region and was later cut into several small pieces and fixed onto the receiving site with fibrin glue. All patients were evaluated on the 1st, 7 th, 30th, 90th, 120th and 180th days postoperatively.

Results: The population's mean age was $50.3 \pm 13.4$ years (range 26 to 77 years). There were 17 males (54.8\%) and 14 females (45.2\%). The proportions of eyes with grade 1, grade 2 and grade 3 pterygium were $12.9 \%, 48.4 \%$ and $38.7 \%$, respectively. During the 6-month follow-up, 2 eyes showed granuloma development, which was resolved with the use of topical corticosteroids. There was recurrence of the lesion in 2 eyes (6.5\%). There were no serious complications.

Conclusion: This surgical option offers a safe and effective alternative, especially in cases where there is little conjunctive tissue available.

Keywords: Ocular Surface; Mini-SLET; Pterygium; Granuloma; Fibrovascular

\section{Introduction}

Pterygium consists of an abnormal tissue membrane (fibrovascular tissue) growing in a triangular shape on the outside of the eye that affects the conjunctiva and cornea. It has degenerative (aging), hyperplastic and inflammatory characteristics. Its etiology is multifactorial, but it is believed to be primarily caused by excessive exposure to ultraviolet rays.

Pterygium affects mainly adult men over 30 years of age, although some Brazilian studies have shown equal impairment in both genders [1,2]. It affects an even greater proportion of individuals living in tropical 


\section{Open Access Journal of Ophthalmology}

countries with exposure to ultraviolet radiation and is a highly prevalent condition in Brazil [3].

Patients may be asymptomatic or present subjective symptoms, such as irritation, foreign body sensation, tearing, burning and even visual impairment caused by the induction of astigmatism or impairment of the visual axis [4].

Many forms of treatment have been proposed. In mild cases, the discomfort can be controlled with the use of lubricant eye drops and cold compresses [5]. Advanced cases should be treated with surgery, with recurrence rates ranging from $0-89 \%$. The technique that has produced the best results with the lowest chance of recurrence is the autologous conjunctival transplant, which is currently recognized as the procedure of choice in terms of efficacy and safety by the majority of ocular surface surgeons [6]. Its action is likely due to the promotion of the healing process and restoration of the limbal barrier [7]. However, the technique has some drawbacks, such as the need for viable conjunctival tissue to perform the graft, greater surgical time, due to the large number of sutures needed to fix the graft and foreign body sensation, also caused by the presence of sutures [8].

In this context, the use of fibrin glue, rather than sutures, for fixing the graft to the receiving site has shown promise and leads to shorter surgical time and less postoperative inflammation [8]. Fibrin glue is composed of fibrinogen, coagulation factor XIII, plasminogen, plasma fibronectin and human thrombin and simulates the final stages of the coagulation cascade.

More recently, Sangwan et al. have described the SLET technique (simple limbal epithelial transplantation) for treating limbal cell deficiency after ocular burns, which exploits the benefits of the amniotic membrane as an ideal substrate for the growth of epithelial progenitor cells $[9,10]$. The mini-SLET technique was described by Hernandez-Bogantes, et al. [11]. In this technique, after removal of the pterygium, limbal epithelial stem cells are used on the amniotic membrane to cover the exposed scleral area. The technique has obtained good efficacy and requires less conjunctiva than a conventional conjunctival autograft. Due to the importance of this condition and with a view to establishing the best treatment, this study aims to evaluate the modified mini-SLET technique in the treatment of primary pterygium.

\section{Methods}

This was a case series conducted with patients with primary pterygium who underwent surgery using the modified mini-SLET technique at the Hospital Universitário Presidente Dutra (President Dutra University Hospital) during the period from June to November 2015.

A total of 40 eyes from 40 consecutive patients underwent the proposed surgery (modified mini-SLET). They were evaluated $1,7,30,90,120$ and 180 days after surgery. The following inclusion criteria were adopted for participation in the study: I) diagnosis of primary pterygium; II) aged 18 years or over; III) indication of surgical treatment due to ocular irritation, induced astigmatism or cosmetic reasons; IV) unilateral condition; and $V$ ) patients who completed 6 months of follow-up. The exclusion criteria were as follows: I) recurrent pterygium; II) pseudopterygium; III) simultaneous nasal and temporal pterygium; IV) patients with glaucoma or intraocular pressure above $21 \mathrm{mmHg}$; V) postoperative allergy to eye drops; VI) presence of coexisting ocular surface diseases, such as dry eye, conjunctivochalasis and eyelid disorders (blepharitis or Meibomian gland dysfunction); and VII) patients with incomplete follow-up or incomplete data.

The modified mini-SLET technique follows pterygium excision and consists of the withdrawal of a $2 \times 4-\mathrm{mm}$ fragment of healthy conjunctiva from the superior temporal region, which is later cut into several small pieces and fixed to the receiving site using fibrin glue (Figure 1).

The pterygia were classified according to morphological characteristics proposed by Tan, et al. (Figure 2) [12]. The same trained and skilled surgeon performed all surgical procedures. Two independent observers performed the pre- and postoperative (PO) evaluations.

On the 1st, 7th and 30th PO days, patients were evaluated regarding the degrees of hyperemia, pain and foreign body sensation. Patients were evaluated for recurrence 6 months postoperatively. Pain and discomfort were evaluated by the patient marking a score from 0 to 10, where 0 represented the absence of ocular discomfort (pain or foreign body sensation) and 10 represented the worst ocular discomfort (pain or foreign body sensation). 


\section{Open Access Journal of Ophthalmology}

Conjunctival hyperemia was graded by the same independent observer: grade 0 , absent (normal vessels); I, mild (mild vascular injection); II, moderate (diffuse ocular hyperemia); and III, intense (diffuse ocular hyperemia with intense dilation of conjunctival vessels). Any signs of complications or recurrence were verified, defined as tissue invasion exceeding the corneal limbus. The collected data were analyzed electronically using version 19 of the IBM-SPSS statistical program.

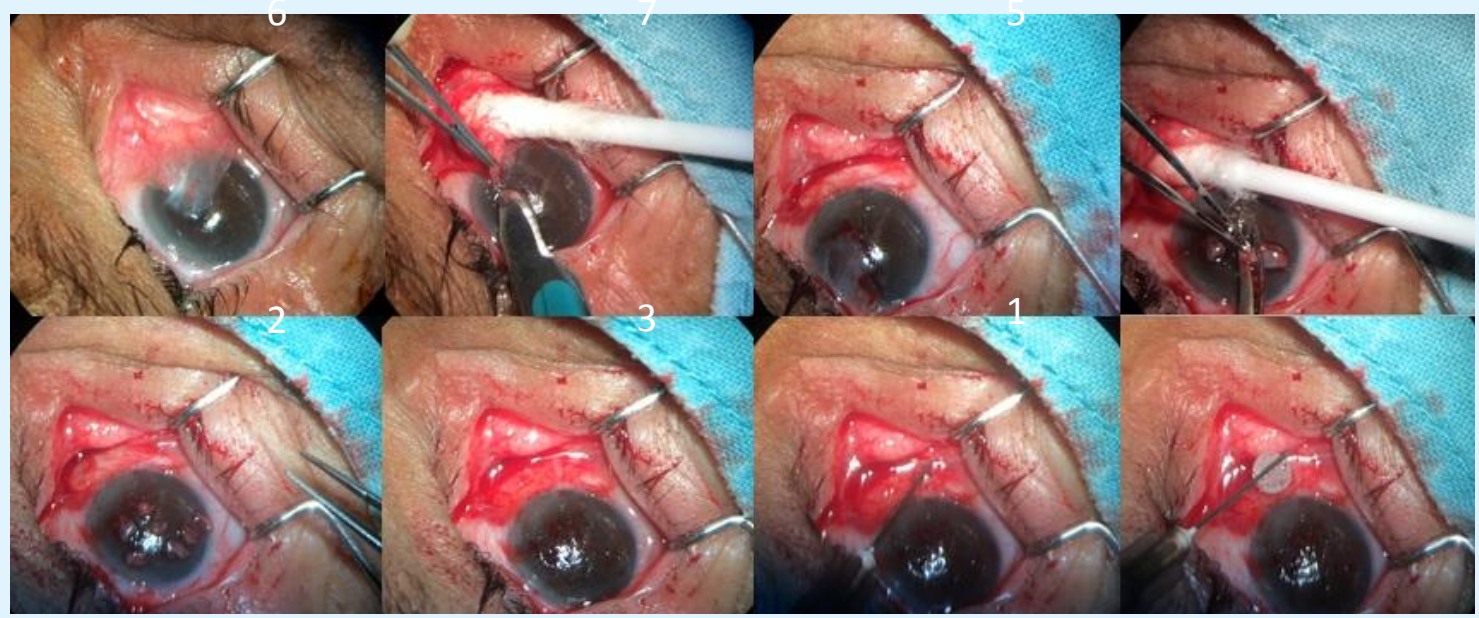

Figure 1: 1. Grade T3 pterygium; 2. Removal of the pterygium head; 3 . Creation of the $2 x 4$-mm conjunctival mini-flap; 4. Division into 8-10 fragments; 5. Conjunctival flap fragments on the cornea; 6. Positioning of the conjunctival fragments on the receptor site; 7. Application of fibrinogen glue portion and factor XIII; 8. Application of thrombin glue portion.

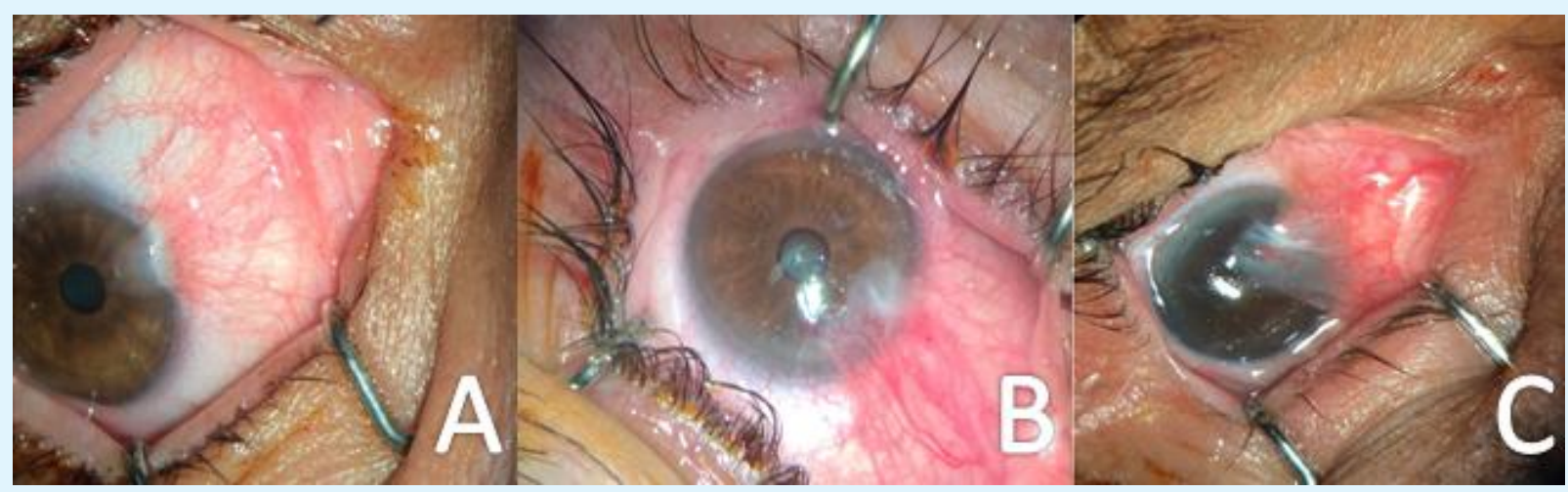

Figure 2: Grading of pterygium according to morphological characteristics. A) Grade T1 (atrophic) episcleral vessels underlying the pterygium clearly visible; B) Grade T2 (intermediate) episcleral vessels are partially obscured; C) Grade T3 (fleshy) episcleral vessels are completely obscured.

\section{Results}

Nine patients did not complete the 6 months of followup (4.5\%); therefore, it was possible to evaluate 31 eyes of 31 patients. The study population's mean age was 50.3 \pm 13.4 (range 26 to 77 ). There were 17 males $(54.8 \%)$ and 14 females (45.2\%). The proportions of eyes with grade 1 , grade 2 and grade 3 pterygium were $12.9 \%, 48.4 \%$ and $38.7 \%$, respectively.

On the first day after surgery, the frequency of patients with a mild degree of hyperemia was $71 \%$ (22 patients), and the frequency of moderate hyperemia was $29 \%$ ( 9 


\section{Open Access Journal of Ophthalmology}

patients). There were no patients with severe hyperemia (Figure 3).

In the analysis of pain on day 1 , the mean level of pain reported by patients, on a scale of 0 to 10 , was $2.58 \pm 2.01$ (Figure 4), with the highest value being 8 and the lowest 0 . The mean score regarding the foreign body sensation analysis was $2.77 \pm 2.09$, with the highest referred value being 7 and the lowest 0 .

On the 7th postoperative day, the frequency of patients with hyperemia degree classified as absent was $48.4 \%$, that of mild was $48.4 \%$, and that of moderate was $3.2 \%$ (1 patient).

Regarding the pain analysis on the 7th day after surgery, the mean pain score reported by patients was $1.23 \pm 0.26$ (range 0 to 5), with 15 patients (48.4\%) reporting no pain. In relation to foreign body sensation, the mean was $1.48 \pm 0.33$ (range 0 to 7 ), with $38.7 \%$ of patients reporting no foreign body sensation. On the 30th day after surgery, hyperemia was absent in 22 patients (71\%). The mean pain was $0.47 \pm 0.16$, and the mean foreign body sensation was $0.63 \pm 0.26$, with $70 \%$ of patients reporting no pain or foreign body sensation.

On the 90th day after surgery, 90\% of patients had absent hyperemia and reported no pain or foreign body sensation. During the 6-month follow-up, there was recurrence of pterygium in 2 eyes $(6.5 \%)$, and 2 eyes showed granuloma development, which was resolved with the use of topical corticosteroids. There were no serious complications.

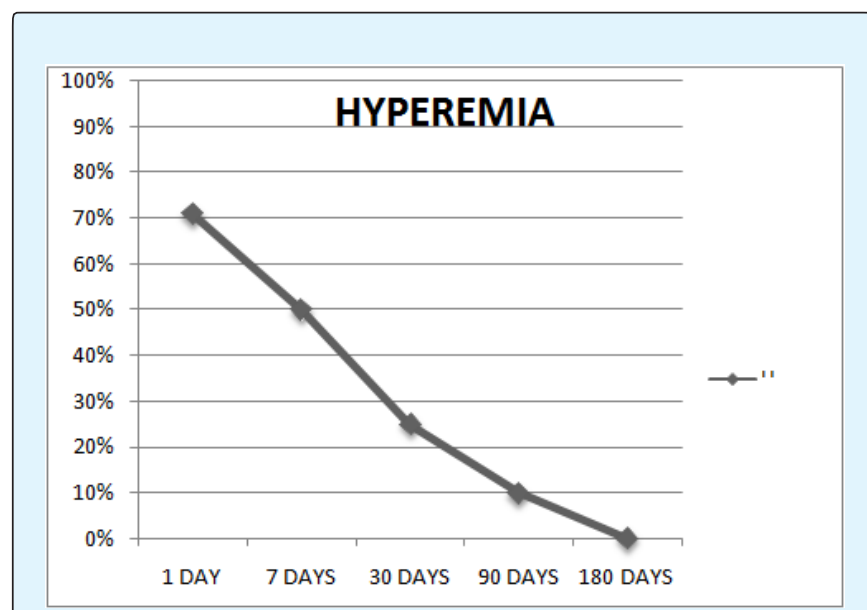

Figure 3: Evaluation of the study participants' postoperative hyperemia.

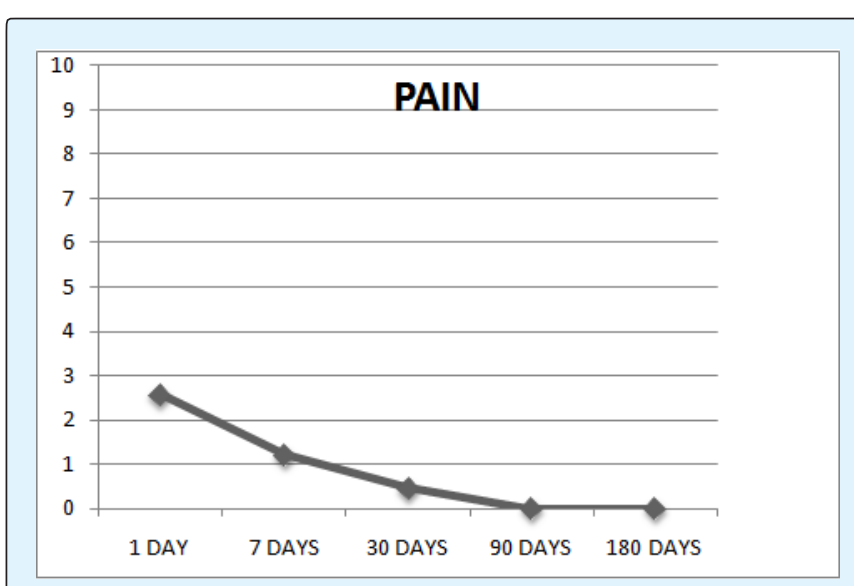

Figure 4: Evaluation of the study participants' postoperative pain.

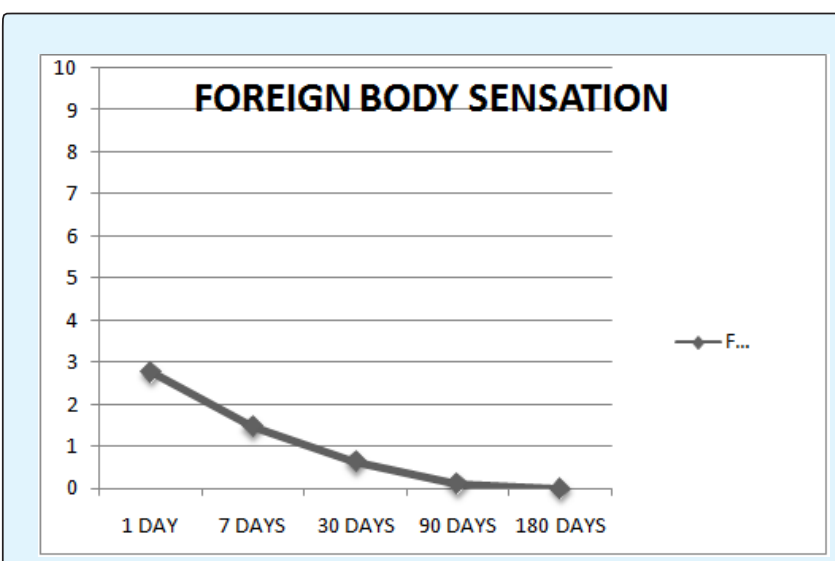

Figure 5: Evaluation of the study participants' postoperative foreign body sensation.

\section{Discussion}

Pterygium is a common ocular surface disease, with a prevalence ranging from 0.3 to $29 \%$ worldwide. ${ }^{13}$ As the rate of recurrence after pterygium surgery is high and can reach up to $89 \%$, numerous adjunctive therapies have been proposed to reduce the recurrence rate [14].

In the 1970s, the treatment of pterygium with beta radiation was quite popular, especially in the United States and Australia. This treatment was performed using strontium-90 and bare sclera. The recurrence rates ranged from $0.5 \%$ to $52 \%$, and complications included conjunctivitis, keratitis punctata, cataract, scleritis and, more rarely, endophthalmitis. These serious complications contributed to a decrease in its use. 


\section{Open Access Journal of Ophthalmology}

The use of antimetabolites, such as 5-fluorouracil (5FU) and mitomycin C (MMC), has been described as an adjuvant pterygium treatment, reducing recurrence by preventing conjunctival proliferation of Tenon's capsule fibroblasts and epithelial corneal cells $[15,16]$. The use of 5 -FU $(50 \mathrm{mg} / \mathrm{ml})$ reduced the recurrence of pterygium to $11 \%$, which is close to the standard technique's recurrence rate of $12 \%$, but with the use of lower doses of 5 -FU (25 mg/mL), recurrence occurred in 36\% of cases [17].

The use of mitomycin $\mathrm{C}$ in the adjuvant treatment of pterygium has proven favorable at a dose of $0.02 \%$, reducing primary pterygium recurrence rates from $32 \%$ to $7 \%$ and recurrent pterygium rates from $45 \%$ to $9 \%$ [18]. The serious complications reported with the use of antimetabolites limit their use in primary pterygia, and their more restricted indication is maintained in recurrent cases or in those with associated symblepharon. The use of higher doses $(0.04 \%)$ showed no additional benefit.

The use of amniotic membrane has also been reported in the treatment of pterygium, due to its antiinflammatory property, its inhibition of angiogenesis and its capacity to cover a large area without the need to remove a large quantity of healthy conjunctiva [19]. When fixed with fibrin glue, the recurrence rate is approximately $5 \%$ to $10 \%[20,21]$.

The advantages of using fibrin glue in pterygium surgery include less surgical time, greater postoperative comfort and less inflammatory cell migration, which lead to less pterygium recurrence [22]. There is no consensus regarding an optimal surgical technique. It is believed that the most effective parameters for evaluation are recurrences, the inflammatory response and the presence of complications [23], which are all aspects used in this study. The mini-SLET technique applied by HernandezBogantes, et al. showed no recurrence in 8 months, and only 1 case of pyogenic granuloma was observed [11]. Therefore, we believe that both recurrence and the granuloma cases encountered in the current study could be minimized with the use of amniotic membrane, which was not used in this study due to the difficulty involved in obtaining it in our service.

We recognize that the evaluation of pain and foreign body sensation using a questionnaire scale is not without bias, especially due to the subjectivity of symptoms, with personal differences in judging the different stimuli; however, in this study, all patients received the same postoperative instructions, given by the same physician. Similar values were found in several studies that also evaluated degrees of ocular discomfort when fibrin glue was used to fix the conjunctival graft [24-26].

This study obtained favorable postoperative results using the modified mini-SLET technique to close the area exposed after pterygium excision. This favorable result was indicated by good postoperative comfort and low rates of recurrence and later complications. The primary limitation of this study is that it is a case series. Further studies, especially randomized clinical trials comparing the new technique with autologous conjunctival transplant, are fundamental to be able to draw better conclusions.

\section{Conclusion}

This surgical option offers a safe and effective alternative, especially in cases where there is little conjunctive tissue available.

\section{References}

1. Jaros PA, De Liuse V (1988) Pingueculae and Pterygia. Surv Ophtalmol 32(1): 41-49.

2. Coroneo MT, Di Girolamo N, Wakefield D (1999) The pathogenesis of pterygia. Curr Opin Ophtalmol 10(4): 282-288.

3. Panchapakesan J, Hourihan F, Mitchell P (1998) Prevalence of pterygium and pinguecula: the blue mountains eye study. Aust N J Ophtalmol 26(1): S2-5.

4. Alves MRA (1999) Pterígio. In: Alves MR. Conjuntiva cirúrgica. São Paulo: Roca, pp: 59-66.

5. Hilgers JH (1960) Pterigium: its incidence, heredity and etiology. Am J Ophtalmol 50: 635-644.

6. Hirst LW (2003) The treatment of pterygium. Surv Ophthalmol 48(2):145-180.

7. Ti SE, Chee SP, Dear KB, Tan DT (2000) Analysis of Variation in success rates in conjunctival autografting for primary and recurrent pterygium. Br J Ophtalmol 84(4): 385-389.

8. Ma DH, See LC, Hwang YS, Wang SF (2005) Comparison of amniotic membrane graft alone or combined with intraoperative mitomycin $\mathrm{C}$ to prevent 


\section{Open Access Journal of Ophthalmology}

recurrence after excision of recurrent pterygia. Cornea 24(2): 141-150.

9. Prabhasawat P, Barton K, Burkett G, Tseng SC (1997) Comparison of Conjunctival autografts, amniotic membrane grafts, and primary closure for pterygium excision. Ophthalmology 104(6): 974-985.

10. Sangwan VS, Basu S, MacNeil S, Balasubramanian D (2012) Simple limbal epithelial transplantation (SLET): a novel surgical technique for the treatment of unilateral limbal stem cell deficiency. $\mathrm{Br} \mathrm{J}$ Ophthalmol 96(7): 931-934.

11. Hernández-Bogantes E, Guillermo Amescua, Alejandro Navas, Yonathan Garfias, Arturo RamirezMiranda, et al. (2015) Minor ipsilateral simple limbal epithelial transplantation (mini-SLET) for pterygium treatment Br J Ophthalmol 99: 1598-1600.

12. Tan DT, Chee SP, Dear KB, Lim AS (1997) Effect of pterygium morphology on pterygium recurrence in a controlled trial comparing conjunctival autografting with bare sclera excision. Arch Ophthalmol 115(10): 1235-1240.

13. Pak KY, Lee JS (2012) Short-term clinical outcomes of pterygium treatment with conjunctival flap advancement. J Korean Ophthalmol Soc 53(12): 17661771.

14. Fernandes M, Sangwan VS, Bansal AK, Gangopadhyay N, Sridhar MS, et al. (2005) Outcome of pterygium surgery: analysis over 14 years. Eye 19(11): 11821190.

15. Johnson RD, Pai V, Hoft RH (2012) Historical approaches to pterygium surgery, including bare sclerae and adjunctive beta radiation techniques. In: Hovanesian JA (Ed), Pterygium; Techniques and Technologies for Surgical Success. Thorofare, NJ, Slack, pp: 27-36.

16. Kirwan JF, Constable PH, Murdoch IE, Khaw PT (2003) Beta irradiation: new uses for an old treatment: a review. Eye 17(2): 207-215.

17. Almond MC, Dastrup BT, Kaufman SC (2012) 5fluorouracil and mitomycin $\mathrm{C}$ : adjuncts to pterygium surgery. In: Hovanesian JA (Ed), Pterygium: Techniques and Technologies for Surgical Success. Thorofare, NJ, Slack Inc, pp: 55-64
18. Valezi VG, Schellini SA, Hata Viveiros MM, Padovani CR (2009) Safety and efficacy of intraoperative 5fluorouracil infiltration in pterygium treatment. Arq Bras Oftalmol 72(2): 169-173.

19. Hayasaka S, Noda S, Yamamoto Y, Setogawa T (1988) Postoperative instillation of low-dose mitomycin $\mathrm{C}$ in the treatment of primary pterygium. Am J Ophthalmol 106(6): 715-718.

20. Hovanesian JA, Behesnilian AS (2012) Pterygium excision with a conjunctival autograft and prophylactic placement of subconjunctival amniotic membrane surrounding the excision site. In: Hovanesian JA (Ed), Pterygium: Techniques and Technologies for Surgical Success. Thorofare, NJ, Slack, pp: 101-110.

21. Barbosa JB, Farias CC, Hirai FE, Gomes JA (2017) Amniotic membrane transplantation with narrowstrip conjunctival autograft vs conjunctival autograft for recurrent pterygia. Eur J Ophthalmol 27(2): 135140.

22. Sharma A, Raj H, Gupta A, Raina A (2015) Sutureless and Glue-free Versus Sutures for Limbal Conjunctival Autografting in Primary Pterygium Surgery: A Prospective Comparative Study. Journal of Clinical and Diagnostic Research 9(11): NC06-NC09.

23. Kenyon KR, Wagoner MD, Hettinger ME (1985) Conjunctival autograft transplantation for advanced and recurrent pterygium. Ophthalmology 92(11): 1461-1470.

24. Alamdari DH, Sedaghat MR, Alizadeh R, ZareiGhanavati S, Naseri H, et al. (2017) Comparison of autologous fibrin glue versus nylon sutures for securing conjunctival autografting in pterygium surgery. Int Ophthalmol pp: 1-6.

25. Park J, Son Y, Suh E (2016) Effect of transverse conjunctival advancement flap surgery for primary pterygium. Canadian Journal of Ophthalmology 51(6): 401-407.

26. Ozdamar Y, Mutevelli S, Han U, Ileri D, Onal B, et al. (2008) A Comparative Study of Tissue Glue and Vicryl Suture for Closing Limbal-Conjunctival Autografts and Histologic Evaluation After Pterygium Excision. Cornea 27(5): 552-558. 